\title{
Kinetics of Nutrient Removal in an Integrated Suspended Growth Reactor
}

\author{
Najib Mohammed Yahya Almahbashi ${ }^{1}$, Shamsul Rahman Mohamed Kutty ${ }^{1, *}$, \\ Yee Ching Chua ${ }^{1}$, Abdulkadir Taofeeq Sholagberu, Aiban Abdulhakim Saeed \\ Ghaleb $^{1}$, Nasiru Aminu ${ }^{1}$
}

${ }^{1}$ Department of Civil and Environmental Engineering, Universiti Teknologi PETRONAS, 32610 Perak, MALAYSIA

*Corresponding Author

DOI: https://doi.org/10.30880/ijie.2019.11.01.019

Received 18 June 2018; Accepted 10 December 2018; Available online 15 May 2019

\begin{abstract}
Wastewater effluent discharge in a large amount of ammonia, nitrate and phosphorus lead to eutrophication the river. Eutrophication is a serious environmental issue that threaten the fishes and aquatic plants. To prevent this from happening, ammonia produced in STP and raw wastewater removal is achieved during nitrification by having an extended aeration while nitrate removal is achieved during denitrification in anoxic tank. In this research study, a pilot plant of integrated suspended growth system (i-SGS) reactor was used to achieve simultaneous removal of ammonia and nitrate. The reactor has three main compartments which are anoxic chamber, aeration camber, and clarifier and operated at a constant flow rate of $720 \mathrm{~L} / \mathrm{d}$ and fixed SRT of 40 days. The RAS time was set to once every 10 minutes for 5 minutes while the IR time is once every 16 minutes for 5 minutes. The wastewater quality parameters, namely chemical oxygen demand (COD), ammonia, and nitrate were measured to determine and evaluate the removal efficiency of them in i-SGS whereas phosphorus was measured to ensure the effluent standard meet the C:N:P ratio requirement. Samples from four sampling points were taken to conduct the laboratory experiment and three replication of the results for each parameter were measured. It was determined that i-SGS was able to eliminate average $72 \%$ of COD at $46 \mathrm{mg} / \mathrm{L}$ of clarifier effluent, and achieved $95 \%$ of ammonia removal at average $1.22 \mathrm{mg} / \mathrm{L}$ of the clarifier effluent concentration while obtained $43 \%$ of nitrate removal in the anoxic tank. Last but not least, the C:N:P ratio obtained was 100:14:8, denoted that i-SGS has ample of nutrients loading provided because it is more than the minimum nutrient requirements, 100:5:1. The removal was possible through the nitrification-denitrification process in the i-SGS pilot plant bioreactor. The operational SRT of 40 days have shown to be effective and stable for the COD but not for nitrifiers. The effluent discharge of COD, ammonia and nitrate in the pilot plant i-SGS has meet the standard requirement of DOE Malaysia, standard A and B respectively.
\end{abstract}

Keywords: Ammonia, denitrification, Integrated System, nitrate, nitrification wastewater treatment.

\section{Introduction}

Discharge in a large amount of nitrate and phosphorus lead to eutrophication or algae bloom in the river. To prevent this phenomenon, effluent discharge of COD, ammonia and nitrate should meet the standard limit set by DOE Malaysia. Nitrate and ammonia content are measured to determine the optimum removal percentage while phosphorus is measured to ensure the effluent standard meet the C:N:P ratio of 100:5:1 requirement [1]. Biological treatment processes for municipal wastewater used is suspended growth. Suspended growth processes are mainly take place in the aeration chamber where oxidation, synthesis reaction, and endogenous respiration occurs [2]. On the other hand, the organic matter will be the carbon source for the denitrifying bacteria that responsible for denitrification [3]. A 
submerged membrane bioreactor (MBR) have been introduced to treat artificial sewage by using a heterotrophic nitrifying-aerobic denitrifying bacterial strain, namely Bacillus methylotrophicus L7 [4]. This research has proven that efficiency of nitrogen removal is not only limited by using autotrophic bacteria. A short-cut nitrification-denitrification (SCND) in a membrane bioreactor (MBR) was able to remove more than $90 \%$ of organics and nitrogen [5]. Besides the nitrification-denitrification, the anaerobic ammonium oxidation (Anammox) process combined with partial nitritation process is one of the technology that was discovered to treat high nitrogen content wastewater [6].

\section{Introduction}

\subsection{Experimental Setup and Operation}

Integrated anoxic-aerobic baffled clarifier system that are using in this research is the Integrated Submerged Growth System (i-SGS) reactor. The three main compartments consist in the i-SGS reactor are anoxic chamber (636 L), aeration camber $(894 \mathrm{~L})$, and clarifier $(310 \mathrm{~L})$. Fig. 1 illustrates the cross section of a schematic diagram of the pilot plant of i-SGS. i-SGS is functioned with three pumps, namely the RAS pump, IR pump and feed pump. The parameters have been set based on the designer's calculation in order to control the environment. According to the parameters, samples are taken to conduct experiments for further monitoring. The feed pump is set with the constant flow rate of $720 \mathrm{~L} / \mathrm{d}$. The RAS time was set to once every 10 minutes for 5 minutes while the IR time is once every 16 minutes for 5 minutes.

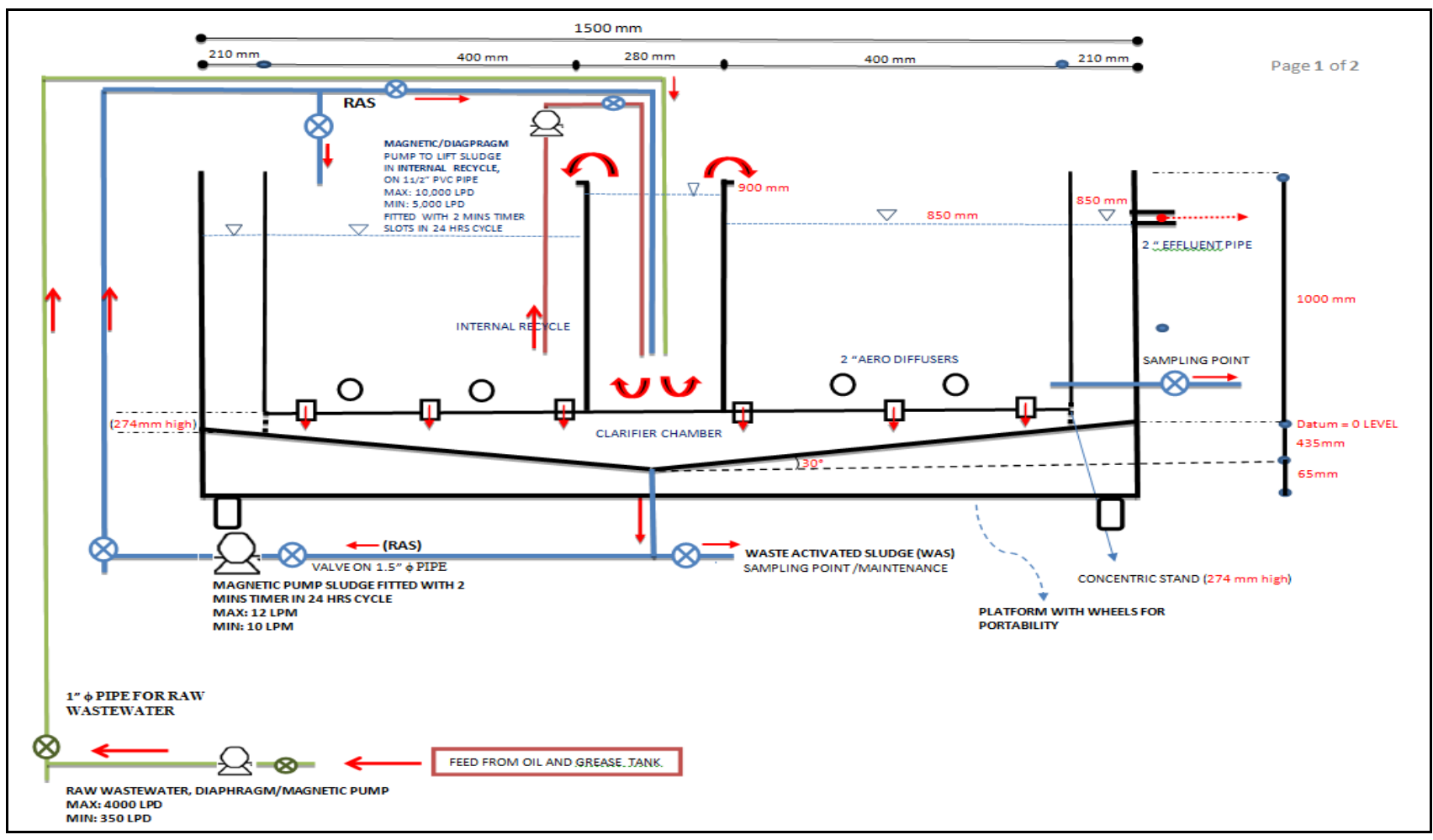

Fig. 1 - Schematic diagram of the i-SGS pilot plant

As observed from the schematic diagram of the i-SGS pilot plant, the influent raw wastewater from UTP's sewage treatment plant (STP) oil and grit chamber is pumped to the anoxic tank through the feed pump where it will overflow into the aeration for further treatment. The purpose of having an anoxic tank in i-SGS is to remove the nitrate by converting it to nitrogen gas. Excess nitrate will lead to eutrophication or algae bloom in natural water bodies and this phenomenon is a threat to fishes and aquatic plants. Hence, the performance of anoxic tank is determined and evaluated by computing the removal efficiency of nitrate in the i-SGS.

The inflow of wastewater in the anoxic tank go to the bottom of the tank will suspend and mix it with the activated sludge. In anoxic tank, the DO concentration is very low but oxidation of organic matter still occurs. When the oxidation of organic matter by the microorganisms is more than DO supply, anoxic conditions is created. Anoxic condition occurs when DO concentration is less than $2 \mathrm{mg} / \mathrm{L}$ and it allow denitrification to take place. Anoxic condition in the anoxic tank turns the microorganism into facultative bacteria when the mixing sludge occurs without the presence of free oxygen. Facultative bacteria can survive in any environment either aerobic or anaerobic condition. In anoxic tank, denitrification take place by converting the product of organic matter after breakdown, which are nitrite and/or nitrate to nitrogen gas. The harmless nitrogen gases are released to the atmosphere which will appear as the 
bubbles in aeration tank. To ensure denitrification process able to happen, readily biodegradable carbon source is needed. Therefore, internal recirculation (IR) and recycle activated sludge (RAS) pumped the sludge into the anoxic tank from the bottom of the clarifier and the aeration tank respectively.

In aeration tank, degradation of organic matter take place. Organic matter (COHNS) from raw wastewater will be oxidized and produce ammonia. The three distinct processes that occurs concurrently in the aeration chamber are oxidation, synthesis, and endogenous respiration. At the same time, air is supplied by the compressor which allow the dissolved oxygen concentration maintains within $2.0-3.0 \mathrm{mg} / \mathrm{L}$ in aeration chamber to ensure all the process take place distinctly. The end product from oxidation, mainly ammonia will be oxidized again into nitrite and nitrate. Aototrophs nitrifiers bacteria such as Nitrobacter and Nitrosomonas are present in the sludge added. The presence of Aototrophs nitrifiers allow nitrification process take place in the aeration tank. The performance of aeration tank is determined by evaluating the removal efficiency of ammonia and COD in i-SGS.

Sludge obtained from the UTP's STP aeration chamber is added into the i-SGS aeration tank to provide food for the microorganism. The sludge is one of the carbon sources for the nitrification and denitrification process. When huge amount of organic matters is degraded, the same amount of ammonia will be produced at the same time in the aeration tank. Therefore, the ammonia content in aeration is higher compared to the anoxic tank. High content of ammonia, nitrate and COD are harmful to the environment and it may cause eutrophication or algae bloom. To prevent ammonia, nitrate and COD from causing harm to the nature, the respective effluent must meet the DOE Malaysia standard regulation.

Wastewater in the aeration tank flow to clarifier though the concentric stand which act as the membrane. In the clarifier, sludge will settle at the bottom and the excess unwanted waste activated sludge (WAS) will be wasted while the recycle activated sludge (RAS) will be recycled back into the aeration to maintain the biomass concentration by RAS pump. Moreover, WAS is used as fertilizer because it contains high nitrate content. The clear treated water will flow out form the pipe and that is the effluent.

\subsection{Sampling Points}

For the research study, four sampling points are collected as the samples are used to conduct experiments. The A, B, C, and D are labeled in the Fig. 1, which shows the exact point of sample collection. The first sampling point was taken from the UTP STP oil and grit chamber (point A), and that sample is influent. The second sampling point is taken from the top of the anoxic tank, which will be the samples for anoxic effluent (point B). The third sampling point is water flow out from the aeration tank, which is the aeration effluent sample (point C). The last sampling point is taken from the pipe that discharge the treated water from clarifier and that is the effluent sample (point D).

Table1 - Sampling points and tests carried out for each point.

\begin{tabular}{lcccc}
\hline & Point A & Point B & Point C & Point D \\
\hline COD & $\sqrt{ }$ & & & $\sqrt{ }$ \\
Ammonia & $\sqrt{ }$ & & & $\sqrt{ }$ \\
Nitrate & $\sqrt{ }$ & $\sqrt{ }$ & $\sqrt{ }$ & \\
\hline
\end{tabular}

All the four samples are used to conduct experiments of nutrients removal. The sampling method used is random sampling where all the samples are taken in different time while the replication for all results are three times.

\subsection{Analytical Procedure}

According to the standard methods of Federation and Association, analytical methods for COD, ammonia, nitrate and phosphorus was conducted. (Method 8030) Nessler Method is used to measure ammonia, (Method 8039) Cadmium Reduction Method is used to determine the nitrate, (Method 8180) Method of Acid Hydrolysable is used to test phosphorus, and (Method 8000) is used to determine COD concentration in wastewater.

\section{Results and Discussion}

\subsection{Results for Ammonia}

Experiment for ammonia was conducted for all the four sampling points as mentioned in methods. Samples are collected and experiments are conducted for every two days. The first date of the experiment was carried out on 12th October 2016. 


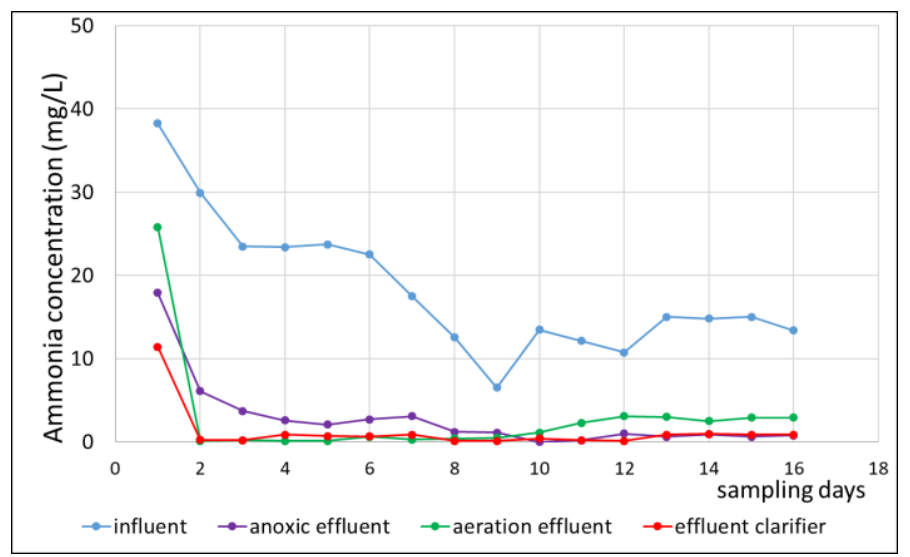

Fig. 2 - Characteristic for ammonia concentration

Fig. 2 shows the ammonia concentration against sampling days. The variations in ammonia influent (blue line) can be explained by the method of sampling taken, which is random sampling. Random sampling means the samples was taken at different time and it is not constant. The highest ammonia concentration was quite constant from day 3 to 6 and this may be due to the time when taking sample was around $8.30 \mathrm{am}$, where most of the students will use the toilet before going to class. However, the concentration seems to have a gradually drop until day 9 . The samples were taken probably in the late afternoon where students no longer use the toilet, hence less ammonia concentration in the influent.

In anoxic effluent concentration (purple line) shows high concentration of ammonia is shown at the beginning of the experiment. This is because the sludge was just added one day before the experiment and the reactor take time to stabilize. Usually the first three days of the reactor operation is still stabilizing period where the results tested might be not accurate. The reading of ammonia in the anoxic tank is quite low because basically there was no ammonia content in the anoxic tank. All of the ammonia has been degraded into nitrate and nitrite through nitrification and denitrification process respectively.

As observed in the aeration effluent (green line), the shape of both graphs looks similar where both of them have high ammonia concentration at the beginning stage and became almost constant after a few days. This is because the system takes time to stabilize. When it starts to stable, the reading of ammonia is almost zero because it has been removed and there should be no ammonia in the aeration. The process of ammonia removal in aeration tank including oxidation which degraded organic matter to ammonia, and nitrification which reduced the ammonia to nitrate.

The concentration of ammonia in the clarifier effluent (red line) is quite high on the 7th day because the RAS pump is not functioning. When the RAS pump failed to recycle the sludge into the aeration tank, they appeared to float on top of the clarifier. Those floating sludge are the organic matter that has been degraded to ammonia but not yet undergo nitrification, this explains why high ammonia concentration was tested. After the floating sludge in the clarifier has been removed and the effluent is clear, the ammonia concentration was going back to the normal ranges.

\subsection{Results for Nitrate}

Fig. 3 shows the result of nitrate concentration vs sampling days. The influent nitrate concentration (blue line) in the UTP STP oil and grit chamber should be low. As observed from the graph, the nitrate concentration on day 2 and day 5 are very high. The only reason that can explained this is because maybe there was a mixing process in the oil and grit chamber that produce some nitrate during nitrification. However, the nitrate reading from day 6 onwards looks normal and within the low ranges.

The nitrate concentration is quite high on the 7th and 8th day because the RAS pump is malfunctioning and it caused too much biomass in the aeration tank. This can relate to the anoxic effluent ammonia concentration, which shows slightly high reading, $3.1 \mathrm{mg} / \mathrm{L}$ on the $7 \mathrm{th}$ day. When the biomass concentration is not maintained in the aeration, the huge amount of organic matter will produce ammonia thus subsequently produce huge amount of nitrate during nitrification. However, the anoxic tank suffers some biomass back flow due to the problem in the feed pump. Sudden drop on the nitrate concentration can be seen from the 9th day in the nitrate anoxic effluent concentration (purple line). Back flow of biomass results in not enough food for the microbes and microbes degrade each other until the organic matter is used up.

From the nitrate aeration effluent concentration (green line), the nitrate concentration in aeration tank is not yet stable for the first three days of operation. The nitrate concentration in aeration tank is not yet stabilize because the autotrophic nitrifiers need longer time to stable even though the heterotrophic bacteria have already stabilized the chemical oxygen demand (COD) concentration. After 3 days of operation, the nitrate concentration reading in the aeration tank seems to have not much different. The sudden drop to $4.8 \mathrm{mg} / \mathrm{L}$ on the 9 th day is because the ammonia in the aeration tank is reduced due to the reduction on organic matter. 
Based on the effluent clarifier concentration graph (red line), the nitrate concentration reach the highest, $15.8 \mathrm{mg} / \mathrm{L}$ on the 2nd day of sampling day. This is because the rector still under stabilizing period where lead to some uncertainty.

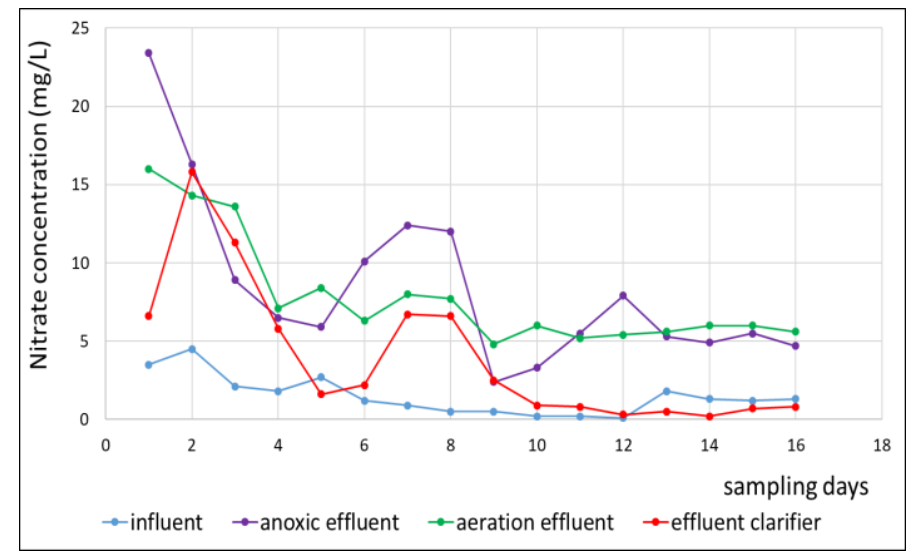

Fig. 3 - Characteristic for nitrate concentration

in the result's readings. On the 7th and 8th day, clarifier is noticed to appear some floating biomass in it. The floating biomass was resulted from the malfunctioning RAS pump that is not able to recycle back the biomass into the aeration tank. In the aeration tank, the nitrate in the biomass which is not being recirculated will remain in the floating sludge. Hence, this cause the nitrate is not being remove from the system.

\subsection{Result for MLVSS}

Fig. 4 show the graph of mixed liquor volatile suspended solid (MLVSS) against sampling days. MLVSS concentration represent the amount of biomass in the system. As observed from the Fig. 4, the reading for the first three days are very high and unstable. This is because the sludge was added one day before the sample was taken. The reactor's system needs at least three days to stabilize. When it starts to stabilize, the readings are quite constant until day 13th. After 14th day, that was the time when the RAS pump is suffered from leakage and a lot of biomass have escaped. Reduction in the biomass volume has caused the MLVSS concentration drops for the following 3 days continuously. Moreover, the amount of biomass in the reactor has affect the concentration of ammonia and nitrate. The source of ammonia was come from the degradation of the biomass (also known as organic matter). Hence, the same amount of biomass will reduce to the same amount of ammonia. This can observe from the ammonia anoxic effluent and aeration effluent concentration results. Furthermore, the nitrate concentration was affected by the ammonia concentration because ammonia will be degraded into nitrate through nitrification process.

Due to the technical problem form RAS pump previously, second run for the sample testing are carried out to determine the i-SGS efficiency. The added sludge for second run was left for one week to achieve stability. As observed from the Fig. 4, the MLVSS concentration are stable throughout the whole testing period. The average MLSS concentration for anoxic effluent and aeration effluent are $4736 \mathrm{mg} / \mathrm{L}$ and $4794 \mathrm{mg} / \mathrm{L}$ respectively while the MLVSS concentration for anoxic effluent and aeration effluent are $3470 \mathrm{mg} / \mathrm{L}$ and $3370 \mathrm{mg} / \mathrm{L}$ respectively.

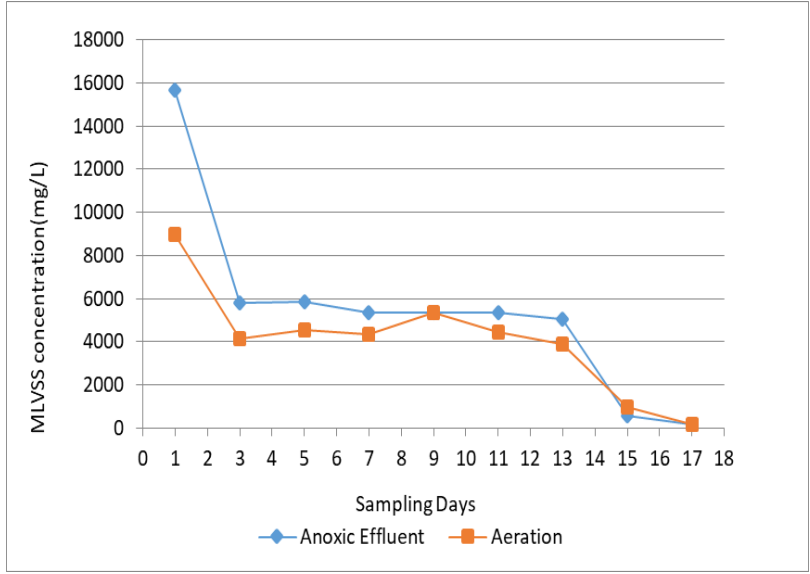

(a)

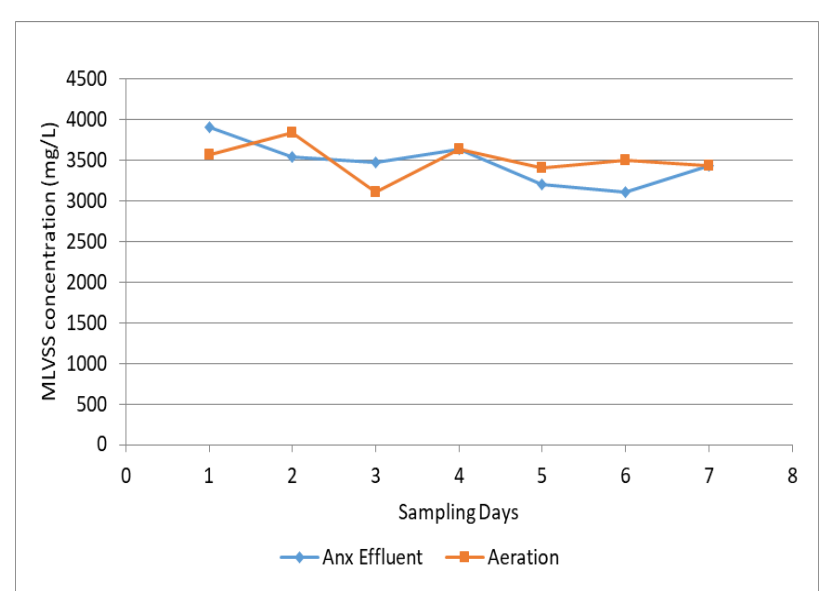

(b)

Fig. 4 - MLVSS concentration (mg/L) vs sampling days (a) $1^{\text {st }}$ run, (b) $2^{\text {nd }}$ run 


\subsection{Results for Removal Efficiency of COD, Ammonia and Nitrate}

COD removal of $72 \%$ was achieved in i-SGS as average value throughout the whole phase at an effluent value of $46 \mathrm{mg} / \mathrm{L}$. There is a slight drop of the removal percentage in last few days before end of the testing period due to the malfunction of the RAS pump.

Ammonia removal efficiency of an average $95 \%$ at $1.22 \mathrm{mg} / \mathrm{L}$ has achieved during the experiment period. At the first sampling day, the removal efficiency is $70 \%$, which is very low because the reactor is still unstable and sludge was just added on day 1 . The ammonia removal is starting to stable afterwards and it remains around $90 \%$ and above, which is very good. Nitrification process in the aeration tank has significantly improved.

Removal efficiency of nitrate obtained the average value of 43\%. From sampling day 6 afterwards, the nitrifiers are getting stabilized and multiplying. However, the result for nitrate removal is very low and did not successfully achieve the desired result. The reason behind this is might because of the dimension of anoxic tank not big enough. The nitrifiers may took longer time to stabilize or the anoxic condition is not sufficient to occur within the detention time. In order to mitigate the problems, the design for anoxic tank has to be re-evaluate and re-calculate in further research. The bio-kinetics coefficients of kd is obtained through Eq. (1):

$$
\frac{\left(S_{0}-S_{e}\right) Q}{X V}
$$

where: $S_{0}=$ influent COD concentration $(\mathrm{mg} / \mathrm{L}), S_{e}=$ effluent COD concentration $(\mathrm{mg} / \mathrm{L}), Q=$ flow rate of the aeration tank, $720 \mathrm{~L} / \mathrm{d}, X=$ MLVSS concentration in the aeration tank $(\mathrm{mg} / \mathrm{L}), V=$ volume of the aeration tank, $894 \mathrm{~L}$.

From Fig. 5, $1 \mathrm{mg}$ of COD removed average $0.0246 \mathrm{mg}$ of MLVSS per day. In every milligram of COD, the microorganism consumed these amounts of sludge to degrade the organic matter. $0.002461 / \mathrm{day}$ is the ' $\mathrm{kd}$ ' value in kinetic equations, also defined as the mass of cells lost during endogenous respiration per unit of time. The graph shows that the amount of microorganism consumed is almost constant because this research did not vary any parameter. However, if the bio-kinetics equation is reversed, every milligram of MLVSS per day/mg COD against the sampling days will produce the amount of bacteria yield. The amount of bacteria yield also can represent the growth rate of microorganism in the aeration tank, denoted as the cell yield coefficient ' $\mathrm{Y}$ ' the kinetic equations.

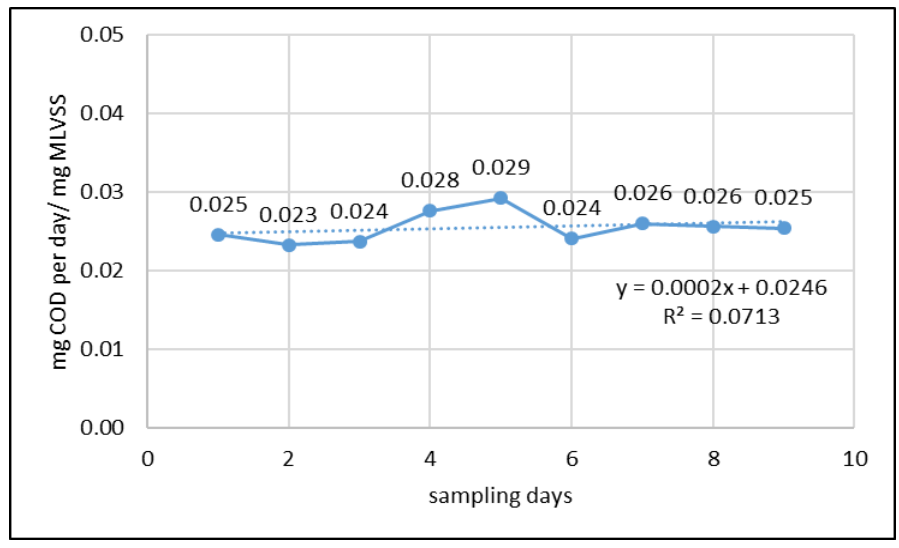

Fig. 5 - mg COD per day/ mg MLVSS vs sampling days

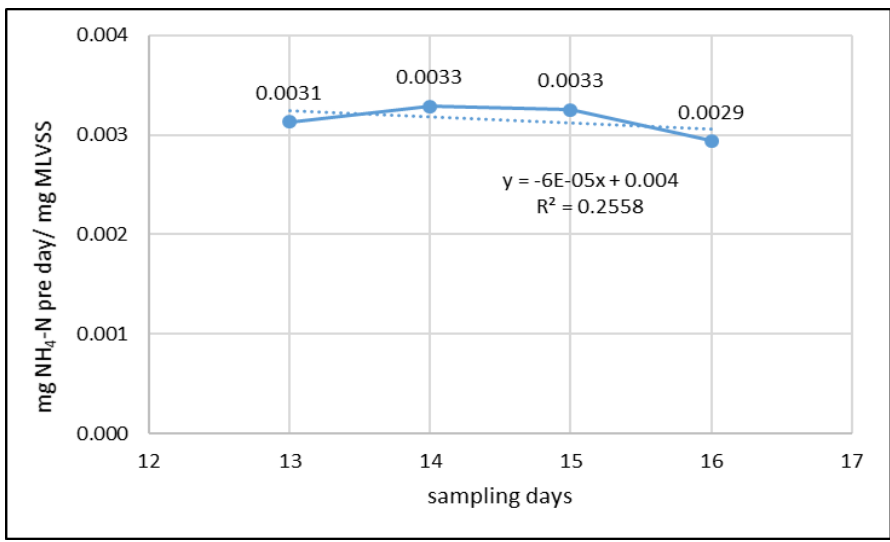

Fig. 6 - mg NH4-N per day/ mg MLVSS vs sampling days 
The effect of substrate on the specific growth rate can be expressed by the graph shown in Fig. 6. The amount of oxidation rate can be measured to quantify how fast ammonium is oxidized to nitrate. The ammonium oxidation rate $(q N)$ for activated sludge is expressed in units of mg NH4-N per day/ mg MLVSS in the aeration tank. After the nitrifier has stabilized, $1 \mathrm{mg}$ of NH4-N per day has removed $0.0032 \mathrm{mg}$ of MLVSS.

Fig. 7 shows the amount of oxidation rate for nitrate to degrade into nitrite and nitrogen gas. The nitrate oxidation rate $(q N)$ for activated sludge is expressed in units of mg NO3-N per day/ mg MLVSS in the anoxic tank. $0.0003 \mathrm{mg}$ of MLVSS is removed in every $1 \mathrm{mg}$ of NO3-N per day.

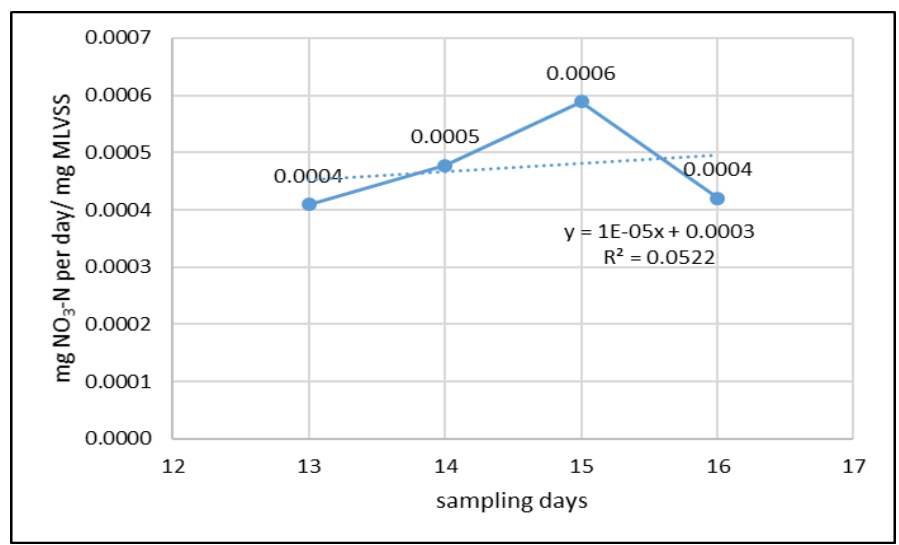

Fig. 7 - mg $\mathrm{NO}_{3}-\mathrm{N}$ per day / mg MLVSS vs sampling days

\subsection{Results for Loading Kinetics od C:N:P ratio}

The minimum nutrient requirements in biological activated sludge treatment system for COD:N:P ratio is 100:5:1. In another words, it means that in every $100 \mathrm{~kg}$ of COD, the bacteria require $5 \mathrm{~kg}$ of nitrogen and $1 \mathrm{~kg}$ of phosphorus. From Table 1, the C:N:P ratio of the i-SGS reactor obtained is 100:14:8. Therefore, there is ample of nutrient loading to feed the bacteria as the $\mathrm{C}: \mathrm{N}: \mathrm{P}$ ratio more than the minimum requirements.

\section{Conclusion}

In conclusion, the i-SGS reactor has been able to accomplish the removal of ammonia and nitrogen in the wastewater. From the results of ammonia and nitrate removal (mg) / MLVSS (d), the removal rate seems to be stabilized at the end of the experimental period. However, the RAS pump was suffered from leakage and caused most of the biomass has escaped during the first run of sample testing. The reduced in biomass concentration has led to the low MLVSS and MLSS concentration, thus effect the removal of ammonia and nitrate. Fortunately, the second run of sample testing for COD is going smoothly and stabled results for MLVSS and MLSS have obtained. The removal for COD, ammonia and nitrate was possible through the nitrification-denitrification process in the bioreactor. These have been proved through the removal efficiency results for COD, ammonia and nitrate to be $72 \%$, $95 \%$ and $43 \%$ respectively. The removal of COD and ammonia in aeration tank are excellent but removal of nitrate in an anoxic tank is low. Therefore, the dimension of anoxic tank needs to be revaluated and redesigned. The operational SRT of 40 days have shown to be effective and stable. Furthermore, the nutrients loading represent in $\mathrm{C}: \mathrm{N}: \mathrm{P}$ ratio has achieved 100:14:8, more than the minimum nutrient requirements. Besides, the effluent parameter values obtained have achieved below the standard set by the Department of Environment (DOE), Malaysia standard A and B. Hence, the objectives are achieved.

\section{Acknowledgement}

The authors would like to thank Ministry of Higher Education for the PRGS grant, Universiti Teknologi PETRONAS (UTP) and all support staff for their contribution in this project.

\section{References}

[1] Marshall, R. (2008). Best Management Practice Guide for Nutrient Management in Effluent Treatment. Marshall Environmental Training and Consulting Group, Forest Products Association of Canada.

[2] Tchobanoglous, G., Burton, F. L., and Stensel, H. D. (2003). Wastewater engineering: Treatment and reuse (5th ed.). New York: Metcalf and Eddy Inc. 
[3] Kutty, S. R. M., Isa, M. H., Nasiru, A., Salihi, I. U., and Ezerie H. (2014). Potential of the compact extended aeration reactor (CEAR) as an integrated system to biologically degrade municipal sewage according to malaysian regulatory limits: Design. Process and Performance, 1, 269-279.

[4] Yao, Y. C., Zhang, Q. L., Liu, Y., and Liu, Z. P. (2013). Simultaneous removal of organic matter and nitrogen by a heterotrophic nitrifying-aerobic denitrifying bacterial strain in a membrane bioreactor. Bioresource Technology, 143, 83-87.

[5] Yao, S., Chen, L., Guan, D., Zhang, Z., Tian, X., and Wang, A. (2017). On-site nutrient recovery and removal from source-separated urine by phosphorus precipitation and short-cut nitrification-denitrification. Chemosphere, $175,210-218$.

[6] Van Hulle, S. W. H., Vandeweyer, H. J. P., Meesschaert, B. D., Vanrolleghem, P. A., Dejans, P., and Dumoulin, A. (2010). Engineering aspects and practical application of autotrophic nitrogen removal from nitrogen rich streams. Chemical Engineering Journal, 162, 1-20. 